\title{
HARMONIZATION AND SYNCHRONIZATION MODEL OF INTERRUPTED TRAFFIC FLOWS ON MOTORWAYS
}

\author{
Goran Kos ${ }^{1}$, Marko Ševrović ${ }^{2}$ Josip Jović ${ }^{3}$ \\ ${ }^{1}$ Institute for Tourism, Zagreb, Croatia \\ ${ }^{2}$ Faculty of Transportation and Traffic Sciences, University of Zagreb, Croatia \\ ${ }^{3}$ ZG-projekt d.o.o., Zagreb, Croatia
}

Submitted 19 December 2014; resubmitted 21 April 2015, 11 August 2015; accepted 26 September 2015;
published online 24 October 2016

\begin{abstract}
The research in this paper focuses on harmonization and synchronization of traffic flows in the period of application of zonal temporary traffic regulation. The specific case scenario addressed in this research implicates that on both carriageways no vehicles were allowed to reside in the work zones for a significant time interval in the same time periods on both sections. In order to solve this problem, the model for harmonization of the traffic flows on dual carriageway motorways with synchronization of opposing traffic flows on both carriageways in special traffic conditions is presented. Actual traffic situation that occurred is presented in order to demonstrate the model, where intensive traffic flows were interrupted on both carriageways during extensive road works on two nearby sections. The model described in this paper has several stages. The first stage implies detailed analysis of traffic flows with computation of expected number of vehicles in the queue. The next stage in the modelling process is to calculate the queue discharge time for both directions and propose measures to optimise operating speed in order to maximize capacity. Then, a graphical method by means of two-way coordination diagram is used to synchronise stop signal timings on all closed sections. This paper shows results of a new model that was developed and implemented in real situations in most complex conditions that can occur on motorways. The research findings have shown the suitability of the proposed model.
\end{abstract}

Keywords: motorway; interrupted traffic flow; temporary signage; traffic volume; harmonizing traffic; flow synchronization; coordination diagram.

\section{Introduction}

The largest traffic load on motorways in Croatia is in tourist season, while in seasons with much less or none tourists the traffic load is very low. Therefore, the traffic load of almost all motorways in Croatia is extremely seasonal. The Average Summer Daily Traffic (ASDT) in the months of July and August is significantly higher than the Annual Average Daily Traffic (AADT) and in some instances it is as much as five times higher (roads in the coastal area).

Given that Croatian motorways are under the highest traffic load in summer months, any works on motorways should be avoided in this season. In addition, this is the period when the conditions on motorways are the most complex and therefore plans for temporary traffic regulation should be in place in this period (e.g. for cases of traffic congestion on tunnel approaches, traffic accidents and redirection of traffic to the opposite carriageway, etc.).
In this paper, we have focused on traffic flows on motorways in complex traffic situations, i.e. during extensive road works in near peak traffic operation. Special situations are situations where traffic flows are either disturbed or stopped (due to weather conditions, incident situations on roads or road works (Kos et al. 2012). Especially complex situations are traffic situations where traffic flows on both carriageways are stopped several times. In such cases a special design for stopping and resuming traffic flows needs to be developed and the traffic flows must be harmonised (Riener et al. 2013). The larger and more inhomogeneous the traffic flow is, the bigger the challenge. Such a complex case is the subject of this paper.

Planning and organising longer-term and complex temporary traffic regulation involves a number of stakeholders, including owners of infrastructure, transport operators, traffic police, etc. (Kos et al. 2012; Vadde et al. 2012). 
The fact that much attention is paid to research and study of temporary traffic regulation in Europe and worldwide is reflected in the fact that over the past two decades comprehensive research has been conducted including analysis of behaviour of traffic participants, as well as analysis of traffic accidents, all aimed at increasing the safety of traffic operation in the areas of temporary traffic regulation especially by conducting the Intelligent Transportation System (ITS) technologies (EU 2010; ETSC 2011). It is also significant that this research is not conducted only in the areas of individual European countries, but often several countries cooperate and participate in the same project with a joint goal of passing the respective legislation and a series of European level recommendations (RSA 1995). The term 'temporary traffic regulation' stands for establishing new traffic regulations of temporary character, occurring due to the impact of various factors. Road works may be considered to be a potentially dangerous situation, not only for traffic participants (drivers and pedestrians), but also for the staff working on the work site.

Proper planning, organisation and implementation of temporary traffic regulation may increase the safety of traffic operation, not only in the area of works, but also on approaches to and exits from such areas. In this way, safer working environment is additionally provided for all workers at the work site. To achieve this, it is extremely important that all stakeholders are included in the processes of planning and organisation, as this is the best way to address any problems that may be anticipated. It is also important that contacts are maintained during execution of works, to facilitate addressing of any unexpected issues that might occur along the way.

The research in this paper focuses on harmonization and synchronization of traffic flows in the period of application of zonal temporary traffic regulation (Wardrop 1952; May 1990; Ullman et al. 2008). The paper includes solution to theoretical aspect of harmonization (adjustment of one traffic flow in case that parts of it are interrupted) and synchronization (adjustment of two opposite traffic flows in case that parts of them are interrupted on two carriageways) of traffic flows during temporary traffic regulation with temporary signalisation on motorway in place (Akçelik et al. 1997). Newer research on this topic is addressed in current literature (Tiaprasert et al. 2015; Rossi et al. 2014; Lee et al. 2015; Clempner, Poznyak 2015).

\section{Description of the Problem}

The traffic problem includes development of a model enabling that as much as possible vehicles pass through two zones of traffic is interrupted over an hour. It is also requested that as few as possible vehicles have two stops in one cycle, and it is necessary to synchronise the passage of the opposite flow at the same time. As the simultaneous optimisation of both flows is not possible, the flow with higher load shall be harmonized first $\left(Q_{1}>Q_{2}\right)$ (Riener et al. 2013; Waller et al. 2009).

In such cases, especially negative, circumstance may come from a high traffic load (e.g. AADT exceeding 15000 vehicles/day) and a large share of heavy vehicles (inhomogeneous traffic flow with more than $20 \%$ share of heavy vehicles).

The general model of the traffic problem is shown in Fig. 1. Double closure of motorway often occurs at the time of hill slope rehabilitation or other road works that could present a hazard to passing vehicles and it should therefore be noted that the temporary traffic regulation during road works must be adjusted to the requirements of these works. This means that the individual zones are open for traffic only over one portion of time within an hour (Fig. 2, $T_{\text {Green }}$ ).

\section{Analysis and Method for Addressing the Problem}

Traffic analysis of capacity includes checking the intensity of traffic flows and their direction on characteristic days. This calls for an analysis of traffic load diagrams on the respective section for the previous time period (1-3 years). If traffic flow intensity of the target year and the previous year is compared (in the exact same time period), variations with respect to the intensity of traffic flows will be minimal unless new traffic conditions have occurred.

This research is crucial for the days used as a basis for computation of queue length and of the time necessary for discharge, harmonization of one-way flows and synchronization of both traffic flows. The disadvantages of addressing flow guiding become more prominent with the increasing length of Zone I and the distance to Zone II, as the harmonized flow disintegrates (major differences occur in individual movement of vehicles in a traffic flow, i.e. the departure from mean speed in a traffic flow increases). Fig. 2 shows the workflow diagram for development of traffic flow harmonization model.

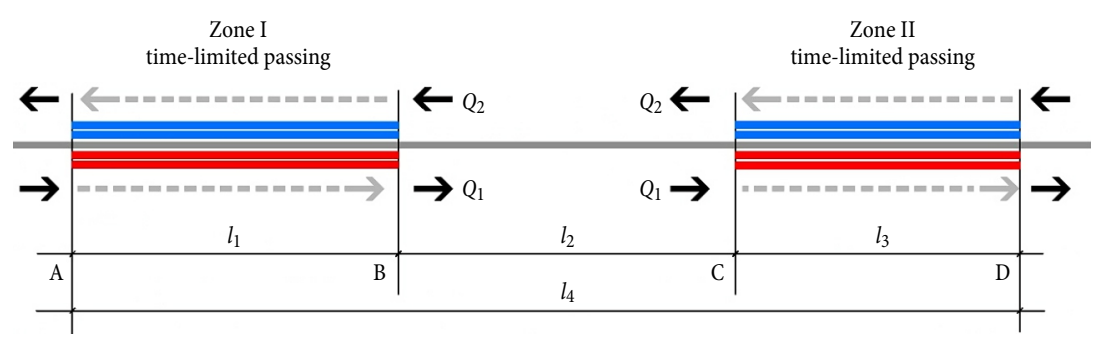

Fig. 1. Traffic problem schema for stopping traffic flows 


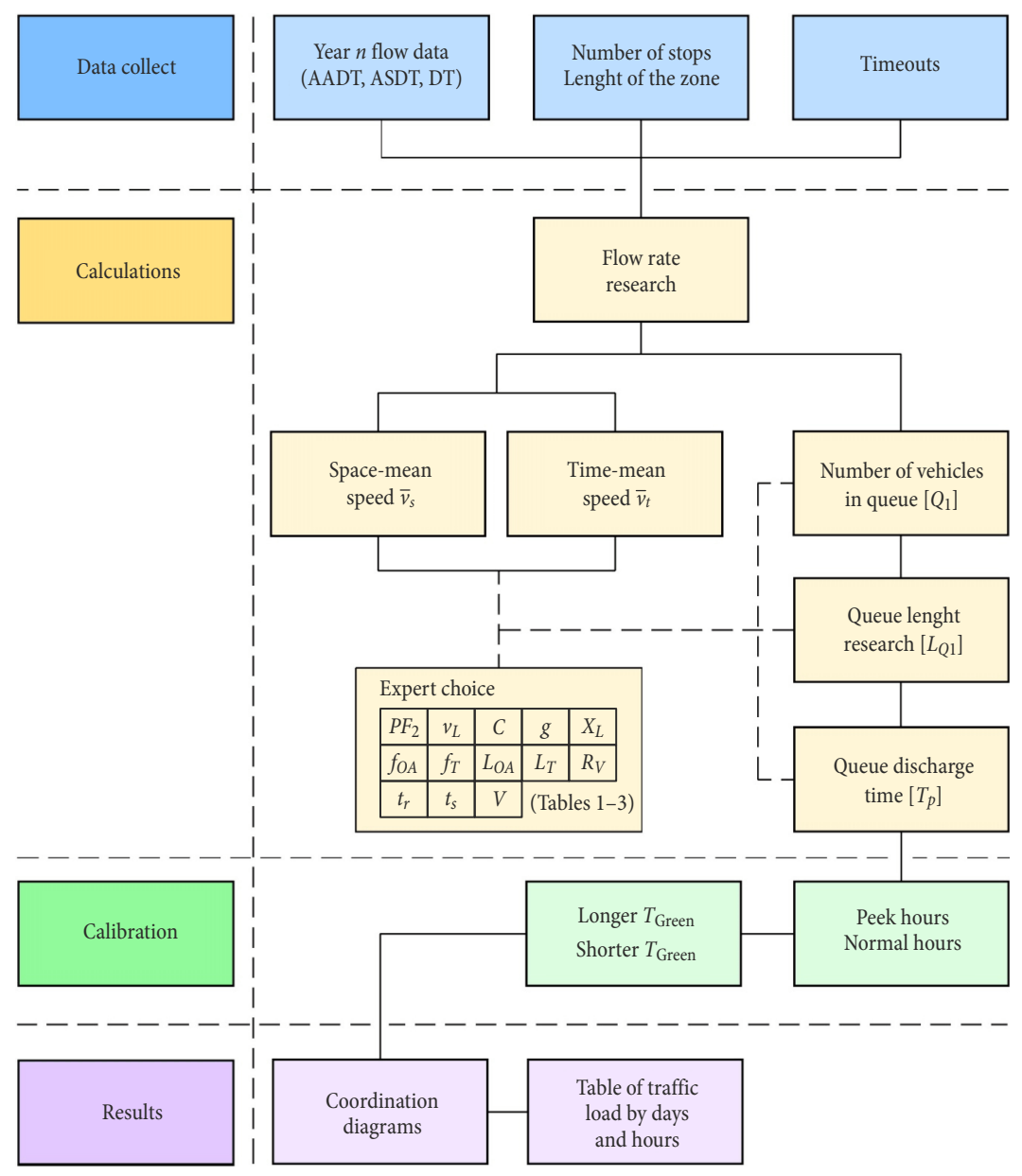

Fig. 2. Workflow diagram for development of traffic flow harmonization and synchronization model

\subsection{Computation of Space-Mean Speed}

The term traffic flow speed explicitly denotes a certain mean value of the speed of all vehicles included in the observed traffic flow (Dadić et al. 2014). Depending on the method of observing flows in relation to space and time and also considering the respective meanings of terms vehicle flow and flow density, the traffic flow theory has established two notions for defining traffic flow speed as the adequate mean value of speed of all vehicles constituting the observed traffic flow. These notions are time-mean speed - flow weighted, in terms of space connected to the cross-section of roadway and in terms of time connected to the period of observing $t$ and space-mean speed - density weighted, in terms of space connected to the section of roadway $s$ and in terms of time connected to the moment (certain point in time) (Akçelik et al. 1997)

Time-mean speed of traffic flow may be obtained by surveying of speeds on the cross-section of the road segment by means of automatic traffic counter. Surveying of speed locally over the period $t$ results in timemean speed as shown in the expression (Highway Capacity Manual 2000):

$$
\bar{v}_{t}=\frac{1}{m} \cdot \sum_{j=1}^{m} \operatorname{tg} \alpha_{i},
$$

where: $\bar{v}_{t}$ - time-mean speed; $\operatorname{tg} \alpha_{i}$ - speed of individual vehicles (related to the cross-section times).

Surveying of speeds on the section at certain point in time provides space-mean speed:

$$
\bar{v}_{s}=\frac{1}{n} \cdot \sum_{i=1}^{n} \operatorname{tg} \beta_{i},
$$

where: $\bar{v}_{s}$ - space-mean speed; $\operatorname{tg} \alpha_{i}-$ speed of individual vehicles (related to the section of the road).

Wardrop established the relationship between timemean speed and space-mean speed according to the expression (Wardrop 1952):

$$
\bar{v}_{t}=\bar{v}_{s}+\frac{\sigma^{2}}{\bar{v}_{s}}
$$

where: $\sigma$ stands for the variance for speeds of vehicles with space-mean speed.

Space-mean speed of traffic flow represents the arithmetic mean of current speeds of all vehicles in a traffic flow on the surveyed motorway section. Spacemean time may be computed with the expression from Garber and Hoel, which was applied in this research (Garber, Hoel 2014):

$$
v_{t}=0.966 \cdot v_{s}+3.541 \text {. }
$$


This enables that the space-mean speed is computed momentarily, and this is the key input for this model. Furthermore, when this model is applied in concrete situation space-mean speed may be obtained comparatively fast, and this again enables quick corrections in coordination. This is especially important when inhomogeneity begins to increase in harmonized traffic due to increased impact of heavy goods traffic.

\subsection{Computation of Queue Length in Zone I}

For computation of maximum anticipated queue length for stopped traffic we have applied the method (Highway Capacity Manual 2000) used for computing queue length resulting from uniform distribution of vehicle arrivals and from the ratio of periods of closed/open traffic. Number of vehicles in the queue is computed with the expression:

$$
Q_{1}=P F_{2} \cdot \frac{\frac{v_{L} \cdot C}{3600} \cdot\left(1-\frac{g}{C}\right)}{1-\left(\min \left(1.0, X_{L}\right) \cdot \frac{g}{C}\right)} .
$$

Table 1. Parameters for computing number of vehicles in a queue

\begin{tabular}{|c|l|c|}
\hline Mark & \multicolumn{1}{|c|}{ Description } & Value \\
\hline$Q_{1}$ & $\begin{array}{l}\text { number of vehicles in initial queue } \\
\text { per lane }\end{array}$ & \\
\hline$P F_{2}$ & correction factor for progression effect & 1 \\
\hline$v_{L}$ & expected traffic load [vehicle/h/lane] & 350 \\
\hline$C$ & cycle duration [s] & 3600 \\
\hline$g$ & effective 'green' time [s] & 900 \\
\hline$X_{L}$ & volume/capacity ratio & 0.25 \\
\hline
\end{tabular}

Source: prepared by authors.

To use expression properly it is necessary to define properly parameters that will be applicable for conditions of traffic operation on motorways. Following the preparation of several scenarios for the observed section, Table 1 shows the parameters used in the development of traffic flow harmonization and synchronization model.

For computation of queue length, average vehicle lengths were used together with average values for spacing between vehicles and the queue length is computed according to the expression (Highway Capacity Manual 2000):

$$
L_{Q}=Q_{1} \cdot f_{O A} \cdot\left(L_{O A}+R_{v}\right)+Q_{1} \cdot f_{T} \cdot\left(L_{T}+R_{v}\right) .
$$

\subsection{Computation of Time Required for Queue Discharge in Zone I}

Queue discharge time is computed according to the empirical expression (Highway Capacity Manual 2000):

$$
T_{p}=Q_{1} \cdot\left(t_{r}+t_{s}\right)+\frac{L_{q}}{V} .
$$

Table 2. Parameters for computation of queue length

\begin{tabular}{|c|l|c|}
\hline Mark & \multicolumn{1}{|c|}{ Description } & Value \\
\hline$L_{q}$ & queue length per lane [m] & \\
\hline$Q_{1}$ & number of vehicles in the queue & 0.8 \\
\hline$f_{O A}$ & $\begin{array}{l}\text { coefficient of the share of passenger cars in } \\
\text { the traffic flow }\end{array}$ & 0.2 \\
\hline$f_{T}$ & $\begin{array}{l}\text { coefficient of the share of goods vehicles in } \\
\text { the traffic flow }\end{array}$ & 4.5 \\
\hline$L_{O A}$ & average passenger car length [m] & 12 \\
\hline$L_{T}$ & average goods vehicle length [m] & 2 \\
\hline$R_{v}$ & $\begin{array}{l}\text { average spacing between stopped vehicles } \\
\text { in the queue [m] }\end{array}$ & \\
\hline
\end{tabular}

Source: prepared by authors.

Table 3. Parameters for computation of queue discharge time

\begin{tabular}{|c|l|c|}
\hline Mark & \multicolumn{1}{|c|}{ Description } & Value \\
\hline$T_{p}$ & time required for queue discharge [s] & \\
\hline$Q_{1}$ & number of vehicles in the queue & \\
\hline$t_{r}$ & driver's reaction time [s] & 0.8 \\
\hline$t_{s}$ & time gap between two consecutive vehicles [s] & 2 \\
\hline$L_{q}$ & queue length per lane [m] & \\
\hline$V$ & discharge speed $[\mathrm{m} / \mathrm{s}]$ & \\
\hline
\end{tabular}

Source: prepared by authors.

Considering the conditions of traffic flow, structure of the traffic and specific circumstances, the conducted analysis of traffic load and computation indicate that the capacity of vehicle passage will be satisfactory for traffic load of up to 500 vehicles/h per direction. This applies for motorway profile in lowland area.

\subsection{Development of Coordination Diagram}

The final step is the development of coordination diagram for the observed traffic flows. To ensure continuous traffic operation on the motorway during traffic stop, passing of vehicles through Zone I needs to be coordinated with Zone II and the opposite traffic flow needs to be synchronized (on the second separate carriageway) (Waller et al. 2009).

Due to the fact, that the sections of traffic stoppage are often of different length, a full coordination of time of vehicle passing in both directions is not possible. Consequently, alternating passing was designed, ensuring minimum waiting time based on the principle of equal distribution for all directions, in the next zone for vehicles that have passed through the previous zone.

The coordination between Zone I and Zone II is shown in diagram in Fig. 3. Passing of vehicles to Zone I may be performed in planned intervals at the beginning of each full hour, while passing of vehicles to Zone II needs to be performed with the offset $T_{\text {Offset }}$ depending on the distance between Zone I and Zone II and on the measured space-mean speed (May 1990). The area bellow the dashed part of the traffic flow is vehicles that 


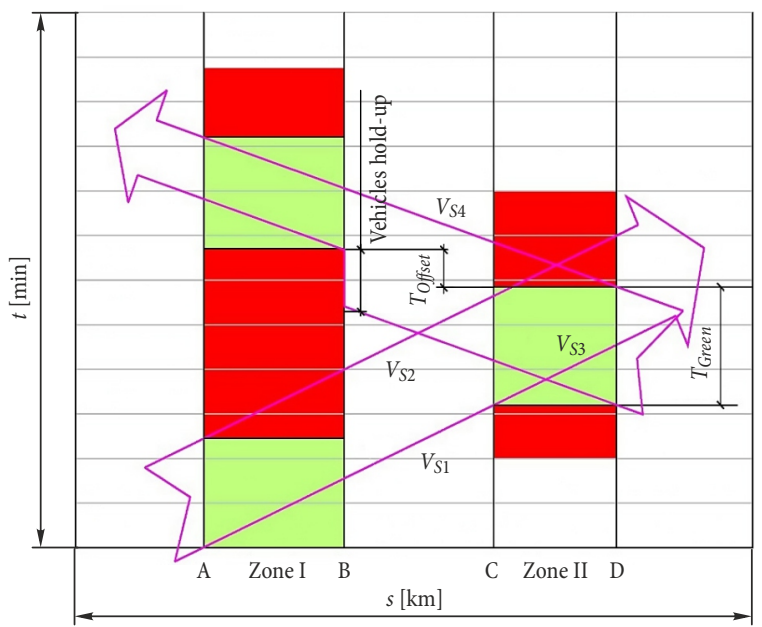

Fig. 3. Travel-time coordination diagram Zone I - Zone II

will certainly pass through the zone when it is free for passage of vehicles, while other vehicles will have to stop once - mostly vehicles from the non-dominant traffic flow (opposite flow).

The expected waiting time when coming to the next section depends on the speed of the vehicle and on the moment when it entered the previous section.

\section{Conclusions}

The road network of the Republic of Croatia includes more than $1240 \mathrm{~km}$ of motorway with prominently seasonal traffic. In summer season the traffic increases several times due to the visits of tourists, mostly from abroad. This is the period of rehabilitation works on carriageways or structures and/or works in motorway green belt, which results in interruptions (disturbance) of traffic flows. The paper presents a new model of harmonization and synchronization of intense traffic flows in complex conditions of zonal temporary traffic regulation for 4-lane motorways and 4-lane freeways. The methods for computing of required traffic data such as space-mean speed, queue length and queue discharge time have been presented. These data represent the basis for development of coordination diagram including synchronization of the opposite, non-dominant traffic flow.

The presented method for harmonization and synchronization of traffic flows has been successfully applied on the Motorway A-3 (Slovenia border - Croatia - Serbia border), during demining works on the area surrounding the motorway between Interchange Novska and Interchange Okučani. This new model can also be applied to all other motorways and highways.

For the application of this method to other cases, some additional notes are in order. In order to accelerate movement of vehicles in queue, 5 minutes prior to actual passing the drivers of vehicles at the distance of up to $100 \mathrm{~m}$ need to be informed that they will soon be passing. Speed should be limited to $80 \mathrm{~km} / \mathrm{h}$ over the entire zone of works to ensure maximum capacity of the roadway. In addition, access to roadside rest areas and/ or all roadside service facilities on the motorway may be prevented if necessary. If there are interchanges between the zones of temporary traffic regulation, then the traffic flows on interchanges also need to be harmonized. And finally, temporary traffic signalisation needs to be provided on main routes, at the distance (measured from the stoppage zone) corresponding to the double maximum expected queue length. Positive effects of traffic flow harmonization are the result of eliminating congestion and traffic accidents, which represent external expenses for the society and especially for the economy and individuals as motorway users. Reduction of direct expenses is reflected in the reduced travel time, reduced fuel consumption and reduced number of lost work hours. Reduction of indirect expenses includes reduced number and consequences of traffic accident and less unfavourable environmental impact. Traffic flow harmonization reduces or gradually counteracts the outflow of traffic from motorways and thus increases revenues from tolls. The increased expenses due to traffic regulation are more than compensated by direct or indirect benefits of avoided congestion during execution of works.

\section{Acknowledgements}

The authors would like to thank the employees and experts of Croatian Motorways Ltd - Sector for Road Maintenance in Zagreb, for their assistance in collecting input traffic data for the presented method and its implementation in October 2012 during human land demining.

\section{References}

Akçelik, R.; Chung, E.; Besley, M. 1997. Recent research on actuated signal timing and performance evaluation and its application in SIDRA 5, in 67th Annual Meeting of the Institution of Transportation Engineers: Compendium of Technical Papers (CD), 3-7 August 1997, Boston, US, 1-17.

Clempner, J. B.; Poznyak, A. S. 2015. Modeling the multi-traffic signal-control synchronization: a Markov chains game theory approach, Engineering Applications of Artificial Intelligence 43: 147-156. http://doi.org/10.1016/j.engappai.2015.04.009

Dadić, I.; Kos, G.; Ševrović, M. 2014. Teorija prometnog toka. Sveučilišni u Zagrebu, Hrvatska, 227 s. Available from Internet: http://files.fpz.hr/Djelatnici/msevrovic/Teorijaprometnih-tokova-2014-skripta.pdf (in Croatian).

ETSC. 2011. Road Safety at Work Zones. PRAISE Thematic Report 6. Preventing Road Accidents and Injuries for the Safety of Employees (PRAISE). European Transport Safety Council (ETSC). 42 p. Available from Internet: http://etsc. eu/road-safety-at-work-zones

EU. 2010. Directive 2010/40/EU of the European Parliament and of the Council of 7 July 2010 on the Framework for the Deployment of Intelligent Transport Systems in the Field of Road Transport and for Interfaces with Other Modes of Transport. Available from Internet: http://eur-lex.europa. eu/eli/dir/2010/40/oj

Garber, N. J.; Hoel, L. A. 2014. Traffic and Highway Engineering. 5th edition. Cengage Learning. 1296 p. 
Highway Capacity Manual. 2000. Transportation Research Board. $1134 \mathrm{p}$.

Kos, G.; Brlek, P.; Poić, K.; Vidović, K. 2012. Correct temporary regulation in cities in the function of traffic safety, in $X I$ International Symposium 'Road Accidents Prevention 2012', 11-12 October 2012, Novi Sad, Serbia.

Lee, S.; Wong, S. C.; Li, Y. C. 2015. Real-time estimation of lane-based queue lengths at isolated signalized junctions, Transportation Research Part C: Emerging Technologies 56: 1-17. http://doi.org/10.1016/j.trc.2015.03.019

May, A. D. 1990. Traffic Flow Fundamentals. Prentice Hall. 464 p.

Riener, A.; Zia, K.; Ferscha, A.; Ruiz Beltran, C.; Minguez Rubio, J. J. 2013. Traffic flow harmonization in expressway merging, Personal and Ubiquitous Computing 17(3): 519532. http://doi.org/10.1007/s00779-012-0505-6

Rossi, R.; Gastaldi, M.; Pascucci, F. 2014. Empirical analysis of vehicle time headways and speeds on rural two-lane, twoway roads, Transportation Research Record: Journal of the Transportation Research Board 2422: 141-149.

http://doi.org/10.3141/2422-16

RSA. 1995. Richtlinien für die Sicherung von Arbeitsstellen an Straßen. Borgmann GmbH \& Co KG, Dortmund, Deutschland. 166 S. (in German).

Tiaprasert, K.; Zhang, Y.; Wang, X. B.; Zeng, X. 2015. Queue length estimation using connected vehicle technology for adaptive signal control, IEEE Transactions on Intelligent Transportation Systems 16(4): 2129-2140. http://doi.org/10.1109/TITS.2015.2401007

Ullman, G. L.; Finley, M. D.; Pike, A. M.; Knapp, K. K.; Songchitruksa, P.; Williams, A. A. 2008. Studies to Improve Temporary Traffic Control at Urban Freeway Interchanges and Pavement Marking Material Selection in Work Zones. Report No FHWA/TX-08/0-5238-2. Texas Transportation Institute, Texas A\&M University System, US. 228 p. Available from Internet: http://tti.tamu.edu/documents/0-5238-2.pdf

Vadde, R.; Sun, D.; Sai, J. O.; Faruqi, M. A.; Leelani, P. T. 2012. A simulation study of using active traffic management strategies on congested freeways, Journal of Modern Transportation 20(3): 178-184.

http://doi.org/10.1007/BF03325796

Waller, S. T.; Ng, M. W.; Ferguson, E.; Nezamuddin, N.; Sun, D. 2009. Speed Harmonization and Peak-period Shoulder Use to Manage Urban Freeway Congestion. Report No FHWA/TX-10/0-5913-1. Center for Transportation Research, University of Texas at Austin, US. 125 p. Available from Internet: http://ctr.utexas.edu/wp-content/uploads/ pubs/0_5913_1.pdf

Wardrop, J. G. 1952. Some theoretical aspects of road traffic research, Proceedings of the Institution of Civil Engineers 1(3): 325-362. http://doi.org/10.1680/ipeds.1952.11259 